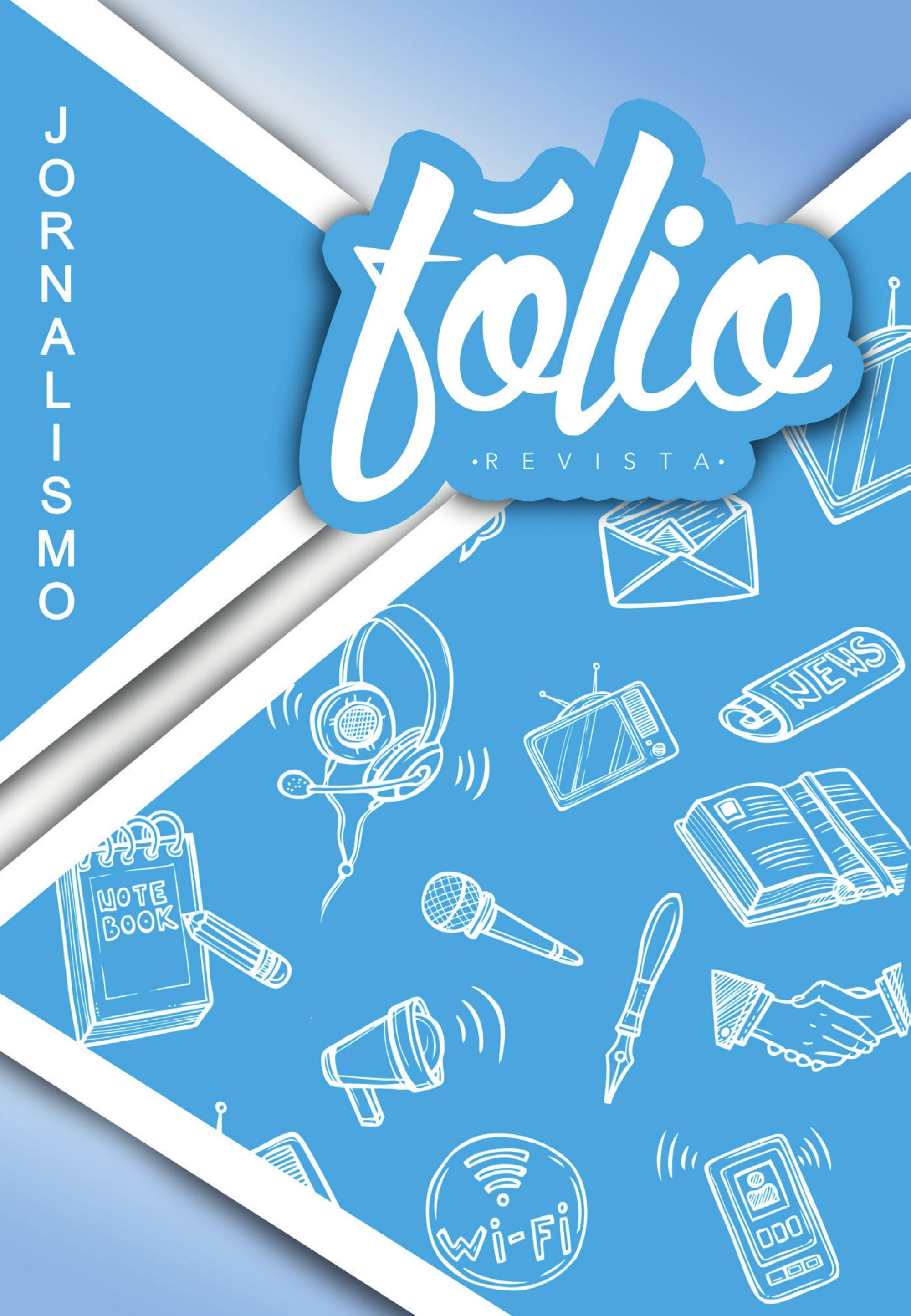




\title{
Letras nos jornais, sexo nas ruas... a prostituição infantil, em terras de imigrantes, é coisa d'O Momento
}

\section{Letters in newspapers, sex on the streets... child prostitution, in immigrant lands, is something of the moment}

\section{Itamar Ferretto Comarú1}

\section{Resumo}

Em 1930, na cidade de Caxias do Sul/RS, os impressos jornalísticos passam a denunciar a prostituição como causa principal para a degradação moral da sociedade de então. Alguns, dentre os quais $O$ Momento, desenvolveriam contínuas reportagens clamando por ações moralizadoras e higienistas por parte do poder público. Com o tempo, as reportagens destacariam tanto a carência quanto a pobreza de alguns grupos sociais ali existentes ligando-os ao frequente aliciamento de crianças e adolescentes para a prostituição infantil. A pesquisa, que se vale do paradigma indiciário e dos pressupostos teóricos da história cultural, contrapõe o mito do imigrante ordeiro, religioso e trabalhador. As ideias e ideais do referido periódico enfrentarão oposições e, ao tornar-se cada vez mais crítico da sociedade de então, terá suas atividades encerradas no ano de 1951. O que destacava em suas páginas não se faz ver perante a historiografia tradicional local ou regional.

Palavras-chave: Cidade. Prostituição. Ações moralizadoras. Higienismo. Caxias do Sul/RS.

\begin{abstract}
In 1930, in the city of Caxias do Sul/RS, journalistic presses began to denounce prostitution as the main cause for the moral degradation of society at that time. Some, among them O Momento, would develop continuous reports calling for moralizing and hygienic actions on the part of the public power. Over time, the reports would highlight both the need and the poverty of some social groups existing there linking them to the frequent enticement of children and adolescents for child prostitution. Research, which draws on the indicium paradigm and the theoretical presuppositions of cultural history, contrasts the myth of an orderly, religious and hardworking immigrant. The ideas and ideals of this periodical will face opposition and, when becoming increasingly critical of the society of that time, will have its activities closed in the year 1951. What stood out in its pages does not appear before the traditional historiography local or regional.
\end{abstract}

Keywords: City. Prostitution. Moralizing actions. Hygiene. Caxias do Sul/RS.

1 Doutorando em Educação, mestre em Turismo e licenciado em História pela Universidade de Caxias do Sul - UCS. Membro do Grupo de Pesquisa em História da Educação, Imigração e Memória da Universidade de Caxias do Sul - GRUPHEIM/UCS. Bolsista CAPES -

Coordenação de Aperfeiçoamento de Pessoal de Nível Superior. Contato: ifcomaru@gmail.com 


\section{Introdução}

( roduto de imaginários, pranchetas e decisões políticas de toda ordem, a cidade de Caxias do Sul surge, ao longo do último quartel do século XIX, como uma localidade originária das antigas Colônias Imperiais de Imigração Europeia edificadas na região Nordeste do Rio Grande do Sul. Superada sua fase colonial, a partir da chegada do trem, em 1910, ela passaria a manifestar em suas ruas as novas e intensas formas tanto de ser quanto de estar e transformar o mundo social que agora se fazia perceber. Assim, nas primeiras décadas do século $X X$, para os impressos locais, dentre os quais $O$ Momento, a cidade de Caxias do Sul seria percebida como um intenso palco perante as dinâmicas transformações que ali aconteciam, de modo que suas páginas surgiam como representações textuais do cotidiano local.

Jeronymo Neves, ao desenvolver a coluna 'Caxias de ontem e hoje', traçaria a conexão entre a chegada do trem e o desencadeado processo transformador. Para ele, antes de tal acontecimento Caxias possuiria a "phisionomia bucólica dos sítios propícios á vida contemplativa, aonde o corpo e o espírito repouzão na paz endêmica das remançosas estancias, no seio acolhedor e tonificante da madre Natureza" (O MOMENTO, 1933, $n^{\circ}$ 01). Até então, desse modo, a localidade seria portadora de um aspecto

[...] accentuadamente colonial, impresso na encantadora simplicidade dos costumes ruraes, destacando-se na flammante indumentária do colono, muitos dentre elles ostentando ainda custoso terno de veludo, conservados como relíquias trazidas da pátria distante, punha uma nota de suavíssima poesia no concerto de tua laboriosidade incessante fortalecida e temperada por essa disposição de bom humor, que é um dos traços característicos do italiano. A par de tudo isso, o custo insignificante, permittindo o equilíbrio dos orçamentos domésticos ás famílias de reduzidos e parcos recursos" (O MOMENTO, 1933, n01).

Desse modo, para o articulista, a cidade contemporânea surgiria como uma espécie de
[...] laboratório em que se combinam os elementos integradores do progresso e engrandecimento de um povo, entra, actuando preponderantemente e eficientemente a fecunda operosidade desse povo a população de Caxias, pela sua contractação ao trabalho desde o rude amanho da terra ao carinhoso cuidado dispensado aos diferentes ramos de sua actividade industrial, foi, com todas essas predisposições que são o apanágio da raça, ao factor indispensável ao seu desenvolvimento econômico, propiciando-Ihe, facilitando-Ihe a benéfica actuação ( $O$ MOMENTO, 1933, nº1).

Embora Neves (1933) não deixe muito claro aquilo que considere como 'povo local', a vantagem particular da 'raça' é amplamente destacada por ele. E a 'raça', por base nas leituras e fontes analisadas até aqui, seria o próprio imigrante, ali identificado como imigrante italiano. É essa cidade que o articulista compara à antiga representação, colonial, que mantinha em sua memória desde a época de sua partida; uma cidade satisfatoriamente próspera e progressista mas que, com o passar de vinte anos, "surge a meus ólhos inteiramente transfigurada, na belíssima floração architectonica de seus edifícios, numa phase de surprehendente renascimento, offerecendo á observação de quem a têm visitado, um [...] empolgante exemplo [da] tenacidade realisadôra de um povo" (O MOMENTO, 1933, $n^{\circ}$ 01). Por fim, sua percepção destacaria que, perante o espaço revisitado, "amparada nas solidas bases de uma forte e resistente extructura economica, que lhe assegura a extraordinária operosidade de sua população intelligente e ordeira, hade em futuro não muito distante, emparelhar com as nossas mais cultas e adeantadas urbes" (O MOMENTO, 1933, nº1).

Aparentemente, Neves se esforça para transmitir uma imagem de sucesso e progresso vinculada ao trabalhador imigrante e seus descendentes. $\bigcirc$ trem seria, dentre outras possibilidades, um meio dele receber ainda mais oportunidades decorrentes de seu esforço colonizador que, agora, faria ver seus resultados na cidade progressista que gradualmente se constituía aos olhos de todos aqueles que ali viviam, transitavam ou visitavam. Em sua percepção, os horrores relacionados 
a miséria e ignorância social, aflições, pobreza, sujeira, doenças, trabalhos brutais, frustrações, alcoolismo, medo ou a fome não se fariam perceber, nem mesmo como contraste. A comercialização do sexo, gradualmente, passaria a fazer parte de tal relação de problemas sociais, embora não seja frequentemente abordada.

Desse modo, ambicionando superar a invisibilidade historiográfica, meu estudo procura destacar a corrupção social praticada sobre crianças, jovens e mulheres que seriam explorados pela comercialização da sexualidade, ao passo que dela se valiam para sobreviver ou melhor viver. $A$ independência do sexo como produto urbano a ser consumido parecia atingir todas as classes sociais. Atento, O Momento indicava para a possível degeneração da sociedade Caxiense, ao passo que indiciava para certas perversões, como a frequente prática do sexo pago com menores e adolescentes carentes. Assim, a correlação entre aqueles que vendem o prazer para aqueles que por ele podem pagar passa a estampar as páginas de referido impresso como cenas textuais de um cotidiano que contrapõe a fabula criada sobre o migrante potentemente religioso, ordeiro e trabalhador.

Para desenvolver tal trama, optei pelos princípios teóricos da história cultural e etnográfica. A história cultural procuraria "identificar o modo como em diferentes lugares e momentos uma determinada realidade social é construída, pensada, dada a ler", de modo que, embora "as representações sociais aspirem a universalidade de um diagnóstico fundado na razão, são sempre determinadas pelos interesses de grupo que as forjam" (CHARTIER, 1988, p. 17). Ainda segundo Chartier (1988), as percepções do social não são de modo algum "discursos neutros: produzem estratégias e práticas (sociais, escolares, políticas), que tendem a impor uma autoridade à custa de outros, por elas menosprezados, a legitimar um projeto reformador ou a justificar, para os próprios indivíduos, as suas escolhas e condutas" (CHARTIER, 1988, p. 17). O historiador etnográfico, por sua vez, "estuda a maneira como as pessoas comuns entendiam o mundo. Tenta descobrir sua cosmologia, mostrar como se organizavam a realidade em suas mentes e a expressavam em seu comportamento" (DARNTON, 2001, p. 14).
A percepção das tensões existentes no campo social, evidenciadas perante os impressos jornalísticos locais, destacam a necessidade de atentar aos eventuais interesses que tais publicações ambicionavam concretizar ou representar. Desse modo, considerei importante seguir os procedimentos e recomendações apresentados por Luca (2008) que percebe como fundamental, ao nos debruçarmos sobre tão instigante material,

[...] construir uma longa e representativa série; localizar a(s) publicação(ções) na história da imprensa; atentar para as características de ordem material (periodicidade, impressão, papel, uso/ ausência de iconografia e de publicidade; assenhorar-se da forma de organização interna do conteúdo; Caracterizar o material iconográfico presente, atentando para as opções estéticas e funções cumpridas por ele na publicação; Caracterização o grupo responsável pela publicação; Identificar o público a que se destinava; Identificar as fontes de receita; Analisar todo o material de acordo com a problemática escolhida" (LUCA, 2008, p. 142).

Desse modo, examinei, especificamente, uma longa série de impressos jornalísticos relacionados ao jornal O Momento, publicado entre os anos de 1933 e 1951. Tal periódico possuía uma linha editorial nacionalista, voltada aos interesses do Partido Republicano Liberal - PRL e ao governo de Getúlio Vargas. Tal semanário destacaria em seu primeiro editorial a ambição de ser

[...] o porta voz da direção do P. R. Liberal deste município, defensor dos interesses da comuna, o propugnador do seu progresso, divulgador dos sucessos que de qualquer forma nos interessem, orientador sincero, um catecismo da educação cívica. Jamais baixaremos da altura serena da defesa dos princípios para o plano inferior das polêmicas pessoais, se bem que nessa defesa aos postulados do P. R. L. não darem quartel a ninguém. Queremos que a geração que surge se forme em um ambiente de amor pela pureza do regime, pela fortaleza e progresso moral e material do paiz" (O MOMENTO, 06/01/1933, $n^{\circ} 01$, p. 01). 
Desse modo, sua "linha era bastante conservadora, e as notícias locais eram apresentadas sem uma separação clara entre notícia e divulgação e doutrinação político-partidária" (POZENATO, GIRON, 2004, p. 101). Encerrado o Estado Novo, entretanto, tal jornal seria reestruturado ideologicamente pelos principais opositores do comunismo e socialismo que, aparentemente, passavam a ganhar um possível destaque: a igreja católica que, preocupada "com o avanço do comunismo e julgando leiga a posição de $\bigcirc$ Momento [...] resolveu assumir a direção do jornal. Por interferência direta do bispo de Caxias, que temia o avanço do comunismo, o jornal mudou sua orientação" (POZENATO, GIRON, 2004, p. 113) e voltou suas forças para aquilo que considerava um importante inimigo da sociedade de então. Os tempos eram decididamente outros, e as percepções sociais que emanavam das páginas dos impressos também.

\section{Entre passeios, cartas e olhares, o outro lado da rua}

Se a nova paisagem urbana encantava os que ali chegavam, a efervescência urbana acarretava uma potencialização contínua da vida cultural e mundana... Os cinemas colaboravam para recolonizar pensamentos e interesses e, assim, representam perante suas telas o que de melhor aconteceria na Europa, ou nos EUA, para aqueles que não poderiam se deslocar para os grandes centros ou países. Ou, ao menos, não o fariam com tanta frequência. Bares, cafés, cinemas, teatros, clubes e edificações cada vez mais suntuosas e amplas fazem parte da área central da localidade e, assim, serviam de atrativo para que ainda mais pessoas se incorporassem ao fluxo central...

Como afirma o boletim Memória (1992), o "desenvolvimento gerado na região, a chegada do trem, a luz elétrica - estimulou novos hábitos - e a vida que parecia encardida e tosca quer parecer limpa e polida" (MEMÓRIA, 1992, n09), de modo que o urbano surgia como uma instigante visibilidade das próprias transformações em movimento perante cenas que valorizavam a imponência das edificações, as personalidades locais ou regionais, então percebidas como símbolos de empreendedorismo e trabalho, a beleza feminina, a própria praça ou, por fim, as novas sociabilidades, como o footing, praticado no espaço central, defronte aos bares, clubes, cinemas e cafés, novas ideias e comportamentos que não se fariam ver sem certas tensões sociais. Em Caxias do Sul, segundo Tessari (2013), o

[...] footing [...] era um hábito domingueiro da cidade, importado das grandes capitais, e que envolvia, principalmente, os jovens solteiros. [...] as moças caminhavam em redor das ruas da praça enquanto os rapazes as 'fogueteavam' sentados pelos bancos. Caso houvesse interesse entre as partes, partiam em direção a um café ou uma bombonière próximos a praça para uma conversa. Os jovens ainda tinham à disposição alguns cinemas, como o Cine Central e o Cine Guarani, que exibiam filmes nas matinês. Todos esses locais de sociabilidade juvenil serviam para ver e ser visto na sociedade, assim como para se deixar fotografar, o que se constata pelos olhares cúmplices de alguns retratados para com o fotógrafo. Também, devido à composição da imagem, incluindo diversos elementos modernos na cena (footing, praça, palacetes em estilo eclético, automóvel, etc.), percebe-se que o desejo do fotógrafo era justamente mostrar os novos hábitos citadinos em meio ao cenário urbano. Ao perenizar esse tipo de cena através da fotografia e, após, exibi-la na vitrine do seu estúdio, como era de praxe, Mancuso contribuía para construir e difundir um imaginário moderno acerca da cidade (TESSARI, 2013, p. 68).

Os jornais, por sua vez, nem sempre seriam complacentes com a prática social do footing. Percy A. Lima, ao publicar uma coluna na primeira página do jornal A Época (1939), seguia seu pensamento destacando um evento local voltado tanto a valorização da pátria brasileira, quanto de seu exército, quando destacaria que

Não escondemos a alegria que nos visitou o coração, quando constatámos a presença de homens e senhoras e jovens de ambos os sexos, que acorreram á nossa sede para emprestar á 
festividade a solidariedade firme e expontânea de brasileiros que preferem conhecer e sentir a vida heroica do nosso povo á verem filmes, faserem footings ou se estirarem preguiçosamente, lendo romances ou retalhando reputações alheias (A ÉPOCA, 1939, n³5, p. 01).

Outro ponto destacado perante os impressos seria o ferrenho embate entre os transeuntes e os motoristas, que logo se faria presente. A matéria que segue procura enfatizar tanto as dificuldades quanto os próprios riscos que estariam sujeitados aqueles que almejassem passear fora das limitações do espaço praça Dante:

O ideal seria que o "footing» passasse para as calçadas e interior da Praça Dante. Além de ser mais elegante, seria menos perigoso. Mas, como isso já está na «massa», ninguém arreda, pé da Avenida, trecho fronteiro aos Cafés. Este não é um mal caxiense: - é de todas as cidades. Sempre existe uma rua um pedaço de rua, uma quadra e ás vezes até menos, que em determinadas horas do dia e tais e tais dias da semana, é totalmente tomada pelos «passeadores» no clássico «vai-vem», que outros chamám de «rema-rema». Si é mal de verdade, é mal colectivo. Agora uma diferença, importante, pode ser observada entre os «footings» de lá e o nosso daqui, - é que nas outras cidades o tráfego de automóveis fica interdito durante as horas de movimento, o que nem sempre acontece aqui, onde, não raro, os automóveis andam em promiscuidade com a população que passeia, numa constante e perigosa ameaça, principalmente quando os «saia-blusa» ou outros mais «conservadores» são dirigidos por «acelerados» no guidon. Porém, resumindo e ficando mesmo no que interessa, achamos que a Inspetoria do Tráfego deveria suspender o livre trânsito de automóveis pela quadra da Avenida frente à Praça, quando das costumeiras horas de passeio, que são, em regra, nos dias úteis pela noite e aos domingos e feriados pela manhã e tarde além das primeiras horas da noite. Para os que passeiam de automóvel, não poderá causar desagrado uma pequena volta pela outra extremidade da Praça, passando pelo Largo Duque de Caxias. E depois, é preciso convir que o povo tem direito de passeiar (A ÉPOCA, $\left.1941, n^{\circ} 125\right)$.

Aqueles que não se intimidavam perante críticas sorrateiras, ou mesmo públicas, passariam a ser citados em tais impressos de modo a enfatizar as roupas, os cabelos, os estilos ou as próprias posturas. Assim, "vemos cruzando mossa ruas ou fazendo o 'footing', ali, na praça Dante, o que Caxias tem de mais representativo, sempre a ostentar os trabalhos artísticos das inúmeras Academias de Beleza que se espalham por todos os recantos da cidade" (A ÉPOCA, 1939, nº4, p. 03). Atentos às silhuetas, e aos próprios rigores da moda, algumas pessoas ganhariam destaque perante os observadores da multidão que por ali transitavam:

Senhorinha C. M., jovem e formosa educadora de Caxias, foi vista, domingo último, quando descia a majestosa escadaria de nossa Catedral. Vinha de assistir à missa das 9. A missa chique da cidade. Como estava bonita elegante senhorinha. Vestia, com muito gosto, um finíssimo casaco de pele marrom, gola alta que se casava admiravelmente bem com a saia brique muito bem talhada que senhorinha soube escolher com inteligência e bom gosto. Com seu suave semblante, onde a mais terna doçura de expressão encontrou morada, senhorinha saia àquela hora da igreja, para atravessar a praça em demanda a sua residência, indiferente por completo aos olhares de todos aqueles moços que, encantados, abriam alas á sua passagem [...] Senhorinha Y. G. foi também vista, fazendo o 'footing' na radiosa manhã de domingo passado. Porte mignon, muito bem calçada, trazia um riquíssimo casaco de pele preta, de admirável talhe. Cobria- Ihe a cabeça vistoso chapéu do feltro, abas largas levantadas em círculo, e dele caia em laço final a "final a 'negligé' numa tira de fino véozinho branco. Senhorinha estava realmente maravilhosa. E com que graça conduzia sua fina bolsa de couro preto lavrado (A ÉPOCA, 1939, n04).

Nos jornais, também haveria espaço para cartas relacionadas a amores não correspondidos, paixões secretas ou desilusões decorrentes do próprio footing. Outras, por sua vez, pareciam 
simbolizar os perigos e desilusões decorrentes dos contatos generalizados, de modo que soavam como críticas subliminares aos prazeres encontrados, tanto nas noites da cidade ou em meio ao footing semanal ou dominical. Assim, em uma pretensa carta enviada ao jornal A Época, Rafael Cris descreveria a paixão arrebatadora que lhe tomara impetuosamente em uma noite de sábado. Entretanto, no dia seguinte, quando a encontrara em meio ao footing realizado pela sociedade elitizada de então, tal sentimento se transformaria em vergonha e arrependimento... Perante tais desencantos, a solução seria a necessária adoração a Jesus Cristo.

Tal carta, com ares de conto prescritivo, indiciaria que as raias do delírio e suas decorrencias, quando do surgimento da cidade alguns anos antes, começava a dar sinais de novos e conturbados entendimentos. Desse modo, tal publicação destacava que

[...] ela era morena, alta e elegante. Tipo de muIher que faz sentir algo de extranho em nosso íntimo, em todo o nosso ser. Nascera de uma família pobre. Trabalhava para sustentar-se e ajudar seus pais. Divertimentos para ela eram os bailes realizados em sotões de casas iluminadas com dois bicos de gaz. Foi lá, num desses ambientes que a vi pela primeira vez e, confesso, a sua figura me impressionou. Costumava ir nesses bailes com o fim de variar e de me divertir, procurando, também, compreender esses seres humanos, o sou modo de vida, o seu pensar, as suas aspirações. A minha posição na sociedade, o meu traje, tudo influiu no espirito daquela muIher morena, alta e elegante. Foi assim que dansamos toda a noite. Dansamos com a impetuosidade de dois seres que se compreendem e que comungam o mesmo ideal. Trocamos palavras carinhosas. Acompanhei-a até a sua casa. Sentia-me inebriado por aquele ser. Soletrei um soneto. E, juntos, cantamos o hino do amor. Era sábado. No dia seguinte, ainda sob aquela impressão que me fazia feliz, caminhava no footing da praça. Momentos depois ela apareceu. E, cousa interessante, paralisei. Quiz falar-Ihe, mas não pude. Evitei-a. Qualquer cousa impedia-me de ir até onde ela estava. Compreen- di, naquele instante, a verdadeira significação da minha atitude. É que eu não a amava, não lhe tinha afeição. $O$ que eu sentia era pejo e vergonha de acompanha-la. Então, eu, acompanhar semelhante criatura? Que diriam os outros? Que pensariam os que me vissem? Eu, um ser humano que se julgava predestinado, que queria viver um amor diferente dos outros compreendi que tinha lido 'vergonha de um ser que julgava amar. Vergonha de ser achincalhado pelos outros. Vergonha de ter que ver e suportar sorrisos irônicos. Vivera até então em mundo de ideias que não me deixavam ver a realidade. Naquele instante, desci do terreno do sonho para o real. A minha atitude revelara as minhas ideias. $O$ reformar do mundo era tragado pela revelação inconsciente de suas próprias atitudes... Amanhã é Dia de Natal. Associar-me ei as homenagens que serão prestadas. Áquele que soube amar e compreender os seus semelhantes. Foi um reformador. Curvo-me diante de sua superioridade... (A ÈPOCA, 1939, n³9, p. 02).

A carta do desapaixonado Rafael parece dar continuidade a preocupação de alguns impressos, dentre os quais o jornal O Popular (1930) que, cerca de dez anos antes publicara em suas páginas uma matéria intitulada "Contra a prostituição uma campanha se impõe". Nela consta que, já destacada a preocupação pelo uso social de cocaína e morfina, hoje "temos de abordar um outro assunto, indiscutivelmente, de maior gravidade, pois que além de tudo, é o que prepara o terreno para os vícios de que acima falamos. Queremos nos referir a prostituição de menores, cujos exemplos se repetem com uma frequência alarmante" (O POPULAR, 05/06/1930, nº 78).

Os lupanares caxienses, sob a denominação de 'cabarés' escondem em suas sombras ingênuas criaturas na primeira fase da primavera da vida, que para lá são levadas por perversos e felizes sedutores, que arrebatando-as do lar pobre, mas feliz, sepultam-nas na pior das sepulturas, que é aquela em que, sobre o corpo vivo da vítima, pesa não a terra fria na necrópole, mas a lousa gélida da indiferença e do abandono social. [...] Arrastam-se pelas ruas, alugando o cor- 
po por meia dúzia de tostões, jovens dignas de boa sorte, que para lá foram atiradas por cidadãos de posição social, entre eles casados e chefes de família, aos quais nada aconteceu e quase nada temem (O POPULAR, 05/06/1930, n 78).

O mesmo impresso destacaria, alguns dias depois, a relação existente entre o casal T., que tinha em sua companhia a menor A. R. da S., então com treze anos. A reportagem destaca que a menina passaria a viver maritalmente com o homem, dele engravidando. Manoel L. "procurou por meio de remédios, fazê-la abortar, o que conseguiu com a auxilio da preta Constantina N. d. S." (O POPULAR, 26/06/1930, n 81). Seriam processados e presos.

Algumas edições depois, no mesmo ano, o Jornal Caxias faria ferrenha campanha a favor dos moradores que residiam próximo ao que então eram denominadas de "Zonas onde ficam localizadas as casas de tolerância [...] diariamente há ali desordens, gritos e tiros, pondo tudo numa polvorosa medonha" (JORNAL CAXIAS, 10/04/1930, $\left.n^{\circ} 147\right)$. A casa destacada pelo impresso local estaria localizada na rua Tronca. A prostituição em espaços residenciais, embora causa-se fortes tensões sociais, não era combatida com medidas consideradas rígidas ou disciplinares. Entretanto, o jornal O Momento (1933) afirmava que, por ordem do "sub chefe da $10^{\circ}$ Região Policial, de ora em diante serão encerradas as casas de tolerância às duas horas da madrugada, sendo proibido taxativamente qualquer movimento de entradas como também música, nas mesmas casas daquela hora em diante" (O MOMENTO, 25/01/1933, $n^{\circ}$ 03). Por vezes, algumas prostitutas seriam presas, e até mesmo expulsas da cidade. Seria o caso de C. F. e C. C. que, por desordens, "receberam ordens de desocupar o município" (O MOMENTO, 17/10/1935, n 139).

As tensões pareciam se agravar e, em fevereiro de 1936, O Momento informaria aos seus leitores que "Assim que chegarem as 15 praças pedidas pelo delegado de Polícia Humberto Silveira, serão tomadas enérgicas medidas contra frequência de menores em casas de jogos e pensões de mulheres, e bem como pela repressão da vadiagem" (O MOMENTO, 1936, n 1907). É em tal oca- sião que o impresso radicalizaria sua percepção e, ao relacionar a atuação do Departamento Estadual de Saúde com o próprio Serviço de Polícia Sistemática Sanitária e as ações de parte da população local, destacaria sem meias palavras: "Caxias está materialmente sanada. [...] Entretanto, um dos problemas que está a exigir providencia enérgica, é, sem dúvida alguma, a higienização moral da cidade" (O MOMENTO, 1936, n 1907). Para justificar seu posicionamento destacava que

[...] quem quer que se dê o trabalho de passar alguns instantes na delegacia de Polícia local, constatará o grau de adiantamento e da vergonhosa ausência de moral ou de pudor que vem minando o organismo da chamada inferior classe social e até mesmo média. Ora é um cidadão que ali comparece queixando-se da infidelidade da esposa, ora um pobre pai operário ou jornaleiro que pede proteção da polícia no sentido de fazer casar a filha desonrada pelo namorado ou noivo. Até mesmo um cáften da própria esposa e das cunhadas alias menores, deu com os contatos na polícia. Defendendo-se afirmou que os fatos passavam invertidamente. No dia imediato a polícia deitava mão num solteirão conquistador de menores, especialista na arte, obrigando- o a casar-se com uma pobre órfã de pai e mãe a quem infelicitara. Outros casos foram desfilando pela delegacia, todos no mesmo gênero $(O$ MOMENTO, 1936, n 1907).

A reportagem segue crítica, destacando que, em "poucos dias, 15 casamentos eram celebrados sob a pressão policial, isso não se levando em conta as muitas investigações enviadas a promotoria pública, por delitos contra a honra" (O MOMENTO, 1936, n 1907). Possivelmente investigariam aquilo que a reportagem analisava como a existência de uma "nova e perigosa modalidade para arranjar maridos" (O MOMENTO, 1936, n 1907). Assim, segundo tal impresso, "Pais e mães inescrupulosos, certamente da baixa camada social, possuem determinado número de filhas moças e meninas. Estão desempregados, de quiçá, não gostam do trabalho honrado e tido de seda, o cinema, e, especialmente os automóveis - que fazer então?" (O MOMENTO, 1936, n 1907). 
Instruídas por semelhantes monstros que se dizem pais, essas moças vivem noite e dia perambulando pelas ruas e praças da cidade, provocantemente, em busca de colóquios amorosos e até mesmo sexuais, recebendo em pagamento, dinheiros, presentes, sapatos, etc. Lá pelas tantas da noite regressam a casa onde prestam então, cinicamente, contas de fim do dia (O MOMENTO, 1936, n 1907).

Por fim, a longa reportagem publicada no mesmo jornal em que Neves, o jurista, destacara sua esfuziante percepção sobre a cidade, apenas três anos antes enfatiza: "Já que estamos percorrendo a escandalosa escada da cidade, vamos descer um degrau a mais" (O MOMENTO, 1936, $n^{\circ}$ 1907). Desse modo, segundo o jornal, chegaríamos até a frente de um

[...] certo hotel e [a] certa casa de cômodos, situados no centro da cidade, [...] conhecidos por 'beco da machambomba' ${ }^{2}$ com habitual grupo de brancas, morenas e mulatas que fazem das portas das referidas casas, ponto de encontro com os amantes, ali permanecendo, principalmente à noite, em posição de verdadeiro desafio à polícia de costume (O MOMENTO, 1936, $\left.n^{\circ} 1907\right)$.

A corrupção de menores seria novamente ressaltada ao final da matéria, quando o impresso enfatizaria seu anseio por ações efetivas de fiscalização por parte das autoridades locais "coibindo os abusos enumerados, fazendo conduzir a delegacia, toda e qualquer menor que for encontrada nas ruas e praças da cidade em condições das descritas" para um interrogatório que "apontará os responsáveis pela insegurança dessas criaturas, promovendo-se a consequente responsabilidade criminal daquele ou daquela degenerada. Só assim, nos parece, será devidamente higieni-

2 Segundo Marcolin (2007), maxambomba seria "uma locomotiva mirim que puxava vagões de passageiros [...] corruptela da expressão inglesa machine pump (bomba mecânica) -, como acabou popularmente batizada" e seria utilizada em ferrovias urbanas. Fonte: http://revistapesquisa.fapesp.br/2007/02/01/notempo-da-maxambomba/ zada, enriquecida por uma população honesta e trabalhadora" (O MOMENTO, 1936, n 1907). As estatísticas criminais passam a estampar as páginas dos jornais. Nelas se percebem crimes relacionados a homicídios voluntários e involuntários, brigas, furtos, atentados a propriedade, desobediência e desacato, estupro, abuso de autoridade, envenenamentos, atentado ao pudor, defloramento, roubo de animais, estelionato, danos, roubos, mortes por acidente, introdução de moeda falsa, infanticídio e tentativas de suicídio.

Cerca de um ano após a contundente manifestação do periódico local, a prostituição voltaria as páginas locais com notoriedade, o que serve de indício para o entendimento de que as autoridades legais não teriam atingido, de pronto, seu objetivo perante a tentativa de coibir tal prática. Assim, o jornal informava que "H. M., vulgo Salomé, francesa-judaica, foi proprietária de uma casa de tolerância que constituía verdadeiro cancro social inquisitado no seio das famílias proprietárias e residentes nas circunvizinhanças do antro por ela dirigido" (O MOMENTO, 29/07/1940, n 385). Em tal espaço, as

[...] luzes multicolores, algazarras, bebedeiras e os ensurdecedores "jazz" traziam os moradores das adjacências em constantes sobressaltos [...] Felizmente os poderes públicos e especialmente aqueles que têm o dever de precípuo de velar pela higiene material e moral da cidade, promoveram uma desinfecção em ordem - a proprietária do lugar desocupou o 'beco' e foi andando. Deixou o município. O prédio foi demolido e as suas famílias próximas sentiram-se libertadas de tamanha praga. As máquinas da indústria Salomé funcionaram por largos anos em plena rua Marques do Herval esquina com a rua Vinte de Setembro, há duas quadras, apenas, do principal centro da cidade! (O MOMENTO, 29/07/1940, n³85).

Entretanto, a mesma reportagem demonstrava seu desencanto com alguns setores da sociedade local pois, estaria sendo comentado pela cidade "que pessoas destacadas nos meios sociais e industriais da cidade pretendem mandar construir ali um prédio de alvenaria, destinado ao 
funcionamento de um cabaret!" (O MOMENTO, 29/07/1940, $n^{\circ}$ 385). Como resposta, os vizinhos contrários ao novo velho empreendimento enviariam um memorial contra tal iniciativa ao próprio delegado de Caxias do Sul, assinado por cerca de noventa pessoas, "cuja autoridade prometeu que promoveria em breve, a localização do meretrício" (O MOMENTO, 29/07/1940, n 385). Desinfetar a moral da sociedade local, para tal periódico, parecia ser a palavra de ordem. Para tal, "Doutor Adão [delegado de polícia], por certo, continuando sua aplaudida atitude de higienizar moralmente a cidade, promoverá em breve a localização do meretrício, mais uma medida de ordem pública" (O MOMENTO, 11/12/1941, n 455).

A prostituição nos espaços centrais, e os crimes de toda ordem, não parecia perder folego, apesar das frequentes tentativas de assepsia social e moral desenvolvidas pelo delegado de polícia local, denominado de doutor Adão. Entretanto, ação de cada feito recebia amplos elogios do jornal O Momento que as destacava como necessárias "ações moralizadoras".

Assim, com a chamada "Moralizadora ação policial. Enérgicas providências contra as decaídas", a edição de 03/07/1943, n536 destacaria os esforços da autoridade policial "no sentido de evitar que a vida normal da cidade sofra qualquer alteração ofensiva aos brios e a pacatez caxiense". A matéria segue problematizando aquilo que chamaria de infiltração no "meio das famílias e das moças que fazem seu costumeiro footing, nos passeios fronteiros aos cafés e cinema central, determinou providencias moralizadoras, saneando aquele logradouro público da perniciosa presença das inúmeras decaídas, as quais disputavam lugar de relevo" (O MOMENTO, 30/01/1943, n 515). Chamado, doutor Arão não titubeou e, dentre as "providencias adotadas contra semelhante elemento, figuram determinações no sentido de ficar vedado que tais mulheres tenham acesso público, senão a contar das 16 até as $24: 00 \mathrm{hs}$. Ao ilustre Delegado, nossas efusivas felicitações pela atitude moralizadora que tomou" (O MOMENTO, 30/01/1943, n 515). Assim, a atitude de coibir o livre fluxo social e o contato com o outro, independentemente de seu propósito, era considerado salutar por parte da imprensa da época. Além disso, a atuação do delegado parecia empoderar algumas pessoas da sociedade que propagariam o ódio e a intolerância.

Percebe-se a existência de algumas zonas sombrias perante a formação regional, zonas de exclusão e preconceito aquarteladas em práticas, simbologias e olhares. Desse modo, distanciados da respeitabilidade social, os cidadãos percebidos como não europeus, ali, enfrentaram a dura realidade de, por longa data, serem percebidos como cidadãos de segunda classe. Desse modo, Adami, por sua vez, publicaria um artigo intitulado 'Os incomodados que se mudem' (O MOMENTO, 14/04/1941, n 424, p. 04), onde aborda a visível percepção pelo desprezo ao negro e sua resistência, inclusive emocional, em um espaço social hostil. Tal autor, ao direcionar suas palavras e pensamentos aos que se dispunham a ler o jornal O Momento, aparenta ter um objetivo específico: fixar sob nova perspectiva a intolerância e incivilidade relacionadas ao povo negro residente na cidade de Caxias do Sul ambicionando uma renovação social que romperia as zonas de sombra e silêncio. Para tal destacaria a manifestação realizada por parte dos frequentadores do Café Sport, então localizado na área central da cidade, próximo a chamada Praça Dante Alighieri.

"Varda", afirmaria um dos clientes... Tal chamamento ao olhar fazia menção ao cidadão negro que, ao cruzar a praça, se aproximava, e, fatalmente, ingressaria em um café agora tomado pelo silêncio e indignação. Por fim, outro cliente exclamaria: "Ma, vegnara il giorno que foremo fora que brute bestie li!". O que o cliente, descendente dos colonizadores imigrantes europeus, procura destacar é que chegaria o dia em que aquele animal poderia ser colocado para fora, sem problemas. A brutalidade exacerbada por alguns dos frequentadores do referido café choca, mas faz Adami elaborar um questionamento especialmente impactante: "Qual seria o dia que [tais clientes do Café Sport] esperavam que chegasse [...] no qual deveriam por ordem de um terceiro alguém começar, segundo sua bestial expressão, a matança dos cidadãos brasileiros de cor, no Brasil?" (O MOMENTO, 14/04/1941, n 424, p. 04). Adami, ao relacionar a afirmativa racista ao chamamento da imolação étnica, talvez desvele aquilo que realmente 
ambicionavam tais clientes: eliminar o diferente, manda-lo embora, fazê-lo sumir do espaço que invadira.

Assim, percebe-se que as percepções amparadas somente na pujança e nas beneficies transformadoras, não se manteriam por muito tempo, de modo que, decorrido alguns poucos anos de tão esfuziante percepção sobre a cidade progressista e seus encantos, a acelerada transformação desvelaria seus problemas, dentre os quais a segregação, delinquência e o aumento da criminalidade. Os casos de embriaguez, até então corriqueiros, passam a se relacionar nas páginas dos impressos com a vagabundagem, o desemprego, a prostituição, a muito frequente corrupção de menores, trapaças sociais e, até mesmo, um ainda insipiente tráfico de drogas... A Época, por exemplo, poucos anos antes, já teria destacado, em sua primeira página, a questão dos jovens desamparados que vagueavam pela cidade...

Menores há, a todo momento, espalhados pela urbs, na mais expressiva demonstração de vadiagem. Ao mais das vezes são o fruto amargo de uma série de males e desgraças. Sem pais ou responsáveis, encontram-se, desde cedo ao sabor do minuano da vida. E vão perambulando numa existência fácil e nociva, rindo e chorando, descendo, quasi sempre, óra rápidos, óra lentos, nos degraus do vício e do crime. Terão eles culpa? Nunca escutaram uma voz carinhosa e amiga que os confortassem, estimulando-os para a luta quotidiana. Seus passos nunca foram guiados e, nos momentos mais difíceis, jamais sentiram o contato de um braço protetor. Cresceram. (A ÉPOCA, 20/11/1938, p. 01).

Embora longa, cito a matéria intitulada 'O Natal dos pobres em Caxias', que parece corroborar que a pujança tão propagada não pertencia a todos, especialmente aos pobres e periféricos da localidade:

Graças a iniciativa e ação de espíritos abnegados e bons e a generosa cooperação dos caxienses, os nossos pobres tiveram com que festejar a grande data da cristandade: o Natal. Comovedor e estranho - mixto de alegria e de tris- teza - foi o espetáculo que presenciamos junto aos pobres que residem em nossa cidade, nos dias 24 e 25. Si fossemos contar quantos vimos desfilar ante nós em busca do que ali nas portas lhes era ofertado, subiriamos, entre velhos e crianças, a mais de um milhar. Todas as idades, desde a tenrinha criança pegada ao peito ate a figura simpática do velhinho de 114 anos, e homens e mulheres, estavam representadas nessa população que chorava, não sabemos si de tristeza ou de alegria. Alegria, porquê, bem lembravam por certo, até esse dia não haviam recebido tanta atenção dos que vivem aqui mais em cima com roupas mais bonita Tristeza, porquê haveriam de pensar nos outros 364 dias do ano, talvez com o único conforto de esperar outro $\mathrm{Na}$ tal ou com a saudade do que ficava. De qualquer fôrma, porém, eles, na sua grande humildade, esteriorizavam o seu profundo reconhecimento àquelas distintas senhoras e àqueles filantropos cavalheiros que amavelmente lhes estendiam, em gesto amigo e carinhoso, as mãos cheias, cheias de cousas boas. Roupas, agasaIhos, alimentos, guloseimas, brinquedos, etc, recebiam em profusão, numa distribuição justa e equitativa. $\bigcirc$ ambiente enternecia, ao tempo que espelhava como tudo é relativo na vida dos seres. Naquélas criancinhas inocentes, com feições tristes, dois olhinhos profundos brilhavam numa ância de comprender alguma cousa. Era-lhes tão estranho que lhes estivessem dando tudo àquilo que sempre lhes fora negado. E não fosse o instinto e nem mesmo saberiam o que fazer com aquelas cousas que passavam á sua fortuna. E os velhos?... Que saberia dizer aquele pretinho que o tempo tornou quasi branquinho, como neve em arvore verde? .... Ele, que viveu 114 Natais, encontraria alguma diferença neste último?.... Daria graças por ter vivido tantos anos?... Acredito que sim, porque ali no ranchinho dele - falou dela com o entusiasmo de um jovem - vive a sua companheira, uma velhinha que já não sái de casa. Quantos anos? - Perdeu a conta, porquê vê apenas o coração e este não branquêia nunca. Ele também fazia mais de ano que não via a Praça Dante. Isso, foi parte do Natal que vimos na Sociedade Caxiense de Auxilio aos Necessitados (Scan) e na Sociedade Espirita 
«Fora da Caridade Não Há Salvação» (A ÉPOCA, 01/01/1941, no 112, p. 12).

Em tal momento, a chegada do trem já havia ocorrido há mais de trinta anos. As indústrias e instalações comerciais já não eram mais uma simples novidade, eram, sim, uma consolidação amplamente estabelecida com segurança e representatividade nacional. $O$ footing era um dos tantos indícios que a sociedade havia local havia se alterado drasticamente em pouco tempo, outros mais poderiam ser citados como as próprias edificações, o surgimento de cinemas, teatros, cafés, livrarias... com ampla visualização de um capital simbólico que procuravam evidenciar perante a rápida mudança nos costumes existentes. Gustavo Valduga (2012), ao valer-se de um fundo vinculado a Luiz Napolitano, destacaria que

Os do interior que demandam a acrópole gaúcha, passando por aqui, vêem bem, em Caxias, os primeiros incursos de foros de civilização. Aqui substituem as botas pelos sapatos, o lenço pelo colarinho incômodo, o 'rabo de tatu' pela bengala e as bombachas pelas calças listradas com frisos. Aqui amanhecem, os do campo, com os ruídos dos apitos das fábricas que constituem o mugir das vacas e vêem rodar os automóveis e possantes caminhões ao invés de carro de boi rangedor e estridente. E pelas caçadas passeia o forasteiro admirado, estasiando-se nas belezas da mulher caxiense em seu 'footing' na quadra da praça Dante; olha as construções modernas, as vitrines deslumbrantes; observa o vai e vem que revela o adiantemento civilizador que ingressa a passos largos no antigo 'Campo dos Bugres' e isso constitui para o forasteiro campesino, o primeiro banho que Ihe facilitará desenvoltura no local de destino (VALDUGA, 2012, p. 155).

Para, ao menos parte da população, neste novo tempo, o próprio fluxo humano, as imagens, jornais e revistas ilustradas informavam e, até mesmo, educavam sobre o novo mundo social que se formava, com suas características, valores, modos de ser, portar e estar, além de oferecerem certas estratégias perante o necessário enfretamento ou adaptação. Desse modo, tanto as próprias reportagens, quanto as colunas elaboradas pelos articulistas, os anúncios comerciais ou a própria oferta de prestação de serviços demonstrariam que tal novo mundo seria diferente e transformador, tanto de ideias e ideais quanto das antigas tradições. No entendimento de Berman (2007), onde "quer que o processo ocorra, todas as pessoas, coisas, instituições e ambientes que foram inovadores e de vanguarda em um dado momento histórico se tornarão a retaguarda e a obsolescência no momento seguinte" (BERMAN, 2007, p. 98).

\section{Conclusão}

Nos primeiros anos da década de 1940, em Caxias do Sul, o próprio calor do verão seria relacionado para se contestar determinados papeis sociais e suas tradições de um velho mundo que as pessoas, gradualmente, se libertavam. Assim, destacava o colunista intitulado Zeca Borba, em sua coluna publicada no jornal A Época, quando do início de 1941, nominada 'Em mangas de camisa':

O verão está aí. Chegou abrasador. Em porto Alegre, segundo sabemos, tem se registrado temperatura sem precedentes. Quase 40 graus á sombra. É de torrar [...] Por isso a população da Capital, população culta e acorde com o século XX, em que vivemos, busca todos os meios de minorar o mal. Antes o refugio das praias e arredores. Agora é o casaco e a gravata que estão sendo banidos. Nésta época de materialismo e blitz-kriegs não há mais lugar para convenções sociais. Que importa que se vá aos cafés ou aos cinemas sem casaco, se as moças do tempo sacudiram as modas de suas vóvós e não usam mais meias e nem vestidos até os pés? Quem foi que disse, há cem anos, que cigarro não era coisa para mulher? Quem de nossos avós diria que homens e mulheres, em promiscuidade, vestiriam os trajes de banho usados em 1940? Assim, justifica-se de sobra a campanha contra os casacos e gravatas, nos dias tórridos que correm. Não podemos e nem devemos viver atados a tradições de um passado que já longe vai! Se o casaco nos inco- 
moda, abaixo com o casaco. Se a gravata aperta nosso pescoço, lembrando-nos o martírio de Tiradentes, guardemo-a no roupeiro! Trabalhar e andar pela cidade sem casaco ou sem gravata não indica desrespeito á sociedade como muitos querem fazer crer. Denóta, sim o senso de oportunidade de um povo que vive numa época de grandes transformações. Que se mantém alheio ao pensamento e á vontade do próximo, somente atento ao desejo de minorar os sofrimentos e as provações dos dias que passam!.." (A ÉPOCA, 01/01/1941, n 112, p. 12, grifos meus).

Tais imagens e impressos revelariam para todos aquilo que Berman (2007) viria a definir como um "turbilhão [transformador] da vida moderna [que seria] alimentado por muitas fontes" (BERMAN, 2007, p. 25), dentre as quais se destacariam as "grandes descobertas nas ciências físicas, com a mudança da nossa imagem do universo e do lugar que ocupamos nele; a industrialização da produção, que transforma conhecimento científico em tecnologia, cria novos ambientes humanos e destrói os antigos" (BERMAN, 2007, p. 25), de modo que a contínua aceleração do ritmo de vida geraria

[...] novas formas de poder corporativo e de luta de classes; descomunal explosão demográfica [e migratória], que penaliza milhões de pessoas arrancadas de seu habitat ancestral, empurrando-as pelos caminhos do mundo em direção a novas vidas; rápido e muitas vezes catastrófico crescimento urbano; sistemas de comunicação de massa, dinâmicos em seu desenvolvimento, que embrulham e amarram, no mesmo pacote, os mais variados indivíduos e sociedades; Estados nacionais cada vez mais poderosos, burocraticamente estruturados e geridos, que lutam com obstinação para expandir seu poder; movimentos sociais de massa e de nações, desafiando seus governantes políticos ou econômicos, lutando por obter algum controle sobre suas vidas; enfim, dirigindo e manipulando todas as pessoas e instituições, um mercado capitalista mundial, drasticamente flutuante, em permanente expansão (BERMAN, 2007, p. 25).

Percebe-se que as mudanças sociais estariam pondo abaixo as tradições de uma época que pa- recia não encontrar mais lugar. As relações sociais, os novos meios de transporte e comunicação fazem-no, gradualmente, definhar. Restarão, assim, as nostálgicas beatitudes de um tempo que foi... A maior circulação do dinheiro, as novas ideias, as novas relações culturais, a percepção do sexo como produto, a chegada constante do outro, o desenvolvimento das periferias abala as poucas certezas que restam. A dinamicidade ambicionada, percebe-se, exige uma sociedade igualmente dinâmica. Entretanto, insistia $\bigcirc$ Momento, em 14/06/1947, "E as meninas se degradam:"

Ainda vimos em número alarmante, em proporções berrantes, seguindo ao lado daqueles miseráveis, a legião das meninas que se degradam. É uma doença que campeia desenfreadamente. É um mal que rasga o edifício social do Brasil que deseja sua independência. As meninas pobres que se degradam com 12, 13 e 14 anos representam uma maior tragédia que as menores desviadas, com pais sem energia e sem autoridade, elas caem no local da imoralidade, deixando-se levar pelo oferecimento de um vestido bonito ou de um simples vidro de perfume. É a miséria que gera esse caos apavorante. É o descontrole dos responsáveis. É por essas coisas, por esses dolorosos dramas de dor e infortúnio, aumentam dia-a-dia, as hóspedes das casas do meretrício. Aí está a desgraça, a absoluta perdição. A ruína de uma mocidade que muito poderia fazer pela construção social, econômica e cultural da nossa terra. Outro problema, esse das meninas que se prostituem, clamando atenção dos governantes, daqueles que prometeram reerguer a nossa cidade. Assim começou os tenebrosos dias da queda moral da sociedade francesa $(O$ MOMENTO, 14/06/1947, $\mathrm{n}^{\circ}$ 740).

As transformações que levariam alguns às raias do delírio, poucos anos antes, apresentava, agora, outras faces e, dentre elas estariam representadas tanto a miséria quanto a vulnerabilidade social e a criminalidade, especialmente em meio as crianças e adolescentes que, abandonadas ou prostituídas, ao longo da cidade, complementariam um cenário que, até então, seria visualizado e reproduzido somente como espaço do progresso. 


\section{Referências}

AGIER, Michel. Antropologia da cidade: lugares, situações, movimentos. São Paulo: Editora Terceiro Nome, 2011.

BATISTEL, A. I.; COSTA, R. Assim vivem os italianos. Porto Alegre: EST; EDUCS, 1983.

BERMAN, Marshall. Tudo que é sólido desmancha no ar: a aventura da modernidade. São Paulo: Companhia das Letras, 2007.

BOURDIEU, Pierre. O poder simbólico. Rio de Janeiro: Bertrand Brasil, 1989.

CAXIAS DO SUL. Boletim Memória, 2002, n²3, p. 02.

Boletim Memória, 1992, nº 09, S/P.

CHARTIER, Roger. A história cultural: entre práticas e representações. Alges, DIFEL 82, 1988.

COSTA, Rovílio. Imigração italiana: vida, costumes e tradições. Porto Alegre, Escola Superior de Teologia e Espiritualidade Franciscana, 1975.

DARTON, Robert. O grande massacre de gatos e outros episódios da história cultural francesa. São Paulo: Graal, 2011.

GARDELIN, M.; COSTA, R. Colônia Caxias: origens. Porto Alegre, Suliani Ed. 1993.

Jornal A ÉPOCA

APRESENTANDO. In: A Época, 02/10/1938, nº 01, p. 01. Disponível em: http://memoria.bn.br/DOCREADER/ DOCREADER.ASPX?BIB=097209

N/I. Visitou Caxias o General Valentim Benício. In A Época, 23/11/1942, n 195, p. 01. Disponível em: http:// memoria.bn.br/DOCREADER/DOCREADER.ASPX?BIB=097209

N/I. Ronda Sinistra. In: A Época, 01/01/1942, n 162, p. 05. Disponível em: http://memoria.bn.br/DOCREADER/ DOCREADER.ASPX?BIB=097209

N/I. Círculo brasileiro de Educação Sexual. In: A Época, 05/10/1941, n 150, p. 16. Disponível em: http:// memoria.bn.br/DOCREADER/DOCREADER.ASPX?BIB=097209

N/I. Campo de pouso. In: A Época, 01/10/1939, n 52, p. 02. Disponível em: http://memoria.bn.br/DOCREADER/ DOCREADER.ASPX?BIB=097209

N/I. Aeródromo Municipal de Caxias. In: A Época, 06/11/1938, n06, p. 02. Disponível em: http://memoria.bn.br/ DOCREADER/DOCREADER.ASPX?BIB=097209

LIMA, Percy A. Uma Impressão. In: A Época, 28/05/1939, n 35, p. 01. Disponível em: http://memoria.bn.br/ DOCREADER/DOCREADER.ASPX?BIB=097209

N/I. O footing e os automóveis. In: A Época, 06/04/1941, n 125, p. 02. Disponível em: http://memoria.bn.br/ DOCREADER/DOCREADER.ASPX?BIB=097209 
RIVA, De La. Panorama da cidade. In: A Época, 1939, n 41, p. 03. Disponível em: http://memoria.bn.br/ DOCREADER/DOCREADER.ASPX?BIB=097209

CRIS, Rafael. Uma carta. In: A Época, 25/06/1939, n³9, p.02. Disponível em: http://memoria.bn.br/ DOCREADER/DocReader.aspx?bib=097209\&PagFis=171\&Pesq=pejo e vergonha.

BALEN, Ítalo. Desamparados. In: A Época, 20/11/1938, nº8, p. 01. Disponível em: http://memoria.bn.br/ DOCREADER/DocReader.aspx?bib=097209\&PagFis=162\&Pesq=menores $\mathrm{h} \% c 3 \% a 1$

N/I. O natal dos pobres em Caxias. In: A Época, 01/01/1941, n 112, p. 12. Disponível em: http://memoria.bn.br/ DOCREADER/DocReader.aspx?bib=097209\&PagFis=1\&Pesq $=$

BORBA, Zeca. Em mangas de camisa. In: A Época, 01/01/1941, n 112, p. 12. Disponível em: http://liquid. camaracaxias.rs.gov.br/LiquidWeb/App/View.aspx?c=22891\&p=11

Jornal CAXIAS

N/I. Polvorosas nas zonas das casas tolerância. In: Jornal Caxias, 10/04/1930, n 147, p. 05. Disponível em: http:// liquid.camaracaxias.rs.gov.br/LiquidWeb/App/View.aspx?c=23330\&p=4\&Miniatura=false\&Texto=false

\section{Jornal O MOMENTO}

ADAMI, João Spadari. Os incomodados que se mudem. In: O Momento, 14/04/1941, n424, p. 04. Disponível em: http://memoria.bn.br/DOCREADER/docreader.aspx?BIB=104523

CHAVES, J. Gonçalves. A’ Postos. In: O Momento, 06/01/1933, n 01, p. 01. Disponível em: http://memoria. bn.br/pdf/104523/per104523_1933_00001.pdf

EDITORIAL. O Brasil dos Brasileiros. In: O Momento, 18/07/1938, n² 280, p. 01. Disponível em: http://memoria. bn.br/DOCREADER/docreader.aspx?BIB=104523

NEVES, Jeronymo. Caxias de ontem e de hoje. In: O Momento, 06/01/1933, p. 02. Disponível em: http:// memoria.bn.br/DOCREADER/docreader.aspx?BIB=104523

N/I. As casas de tolerância. In: O Momento, 25/01/1933, nº 03, p. 04. Disponível em: http://memoria.bn.br/ DOCREADER/docreader.aspx?BIB=104523

N/I. Mulheres presas. In: O Momento, 17/10/1935, n¹39, p. 05. Disponível em: http://memoria.bn.br/ pdf/104523/per104523_1935_00139.pdf

N/I. Policiamento. In: O Momento, 10/02/1936, n 156, p. 01. Disponível em: http://memoria.bn.br/ DOCREADER/docreader.aspx?BIB=104523

S. de M. A higiene moral da cidade. In: O Momento, 30/09/1940, n³94, p. 01. Disponível em: http://memoria. bn.br/DOCREADER/DocReader.aspx?bib=104523\&PagFis=1906\&Pesq=moral da cidade

N/I. Um cabaret em promiscuidade com residências familiares? In: O Momento, 29/07/1940, n 385, p. 01. Disponível em: http://memoria.bn.br/DOCREADER/DocReader.aspx?bib=104523\&PagFis=1943\&Pesq=salom\% c3\%a9

N/I. O meretrício no judiciário. In: O Momento, 01/12/1941, n 455, p. 06. Disponível em: http://memoria.bn.br/ 
DOCREADER/DocReader.aspx?bib=104523\&PagFis=1943\&Pesq=salom\%c3\%a9

N/I. Moralizadora ação policial: enérgicas providencias contra as decaídas. In: O Momento, 03/07/1943, n 536, p. 01. Disponível em: http://memoria.bn.br/DOCREADER/DocReader.aspx?bib=104523\&PagFis=1943\&Pesq=sa lom\%c3\%a9

TOENNIGES, Guilherme do Valle. A dolorosa tragédia dos abandonados. In: O Momento, 14/06/1947, n740, p. 01. Disponível em: http://memoria.bn.br/DOCREADER/DocReader.aspx?bib=104523\&PagFis=1943\&Pesq=salo m\%c3\%a9

\section{Jornal O POPULAR}

N/I. Contra a prostituição: uma campanha se impõe. In: O popular, 05/06/1930, n 78, p. 04. Disponível em: http://liquid.camaracaxias.rs.gov.br/LiquidWeb/App/View.aspx?c=51805\&p=3\&Miniatura=false\&Texto=false

N/I. Crime de lenocínio e infanticídio. In: O Popular, 26/06/1930, n 81, p. 01. Disponível em: http://liquid. camaracaxias.rs.gov.br/LiquidWeb/App/View.aspx?c=51808\&p=0\&Miniatura $=$ true\&Texto $=$ true

LUCA, Tânia Regina de. História dos, nos e por meio dos periódicos. In: Fontes Históricas. São Paulo. Contexto, 2005.

POZENATO, Kenia Maria Menegotto; GIRON, Loraine Slomp. 100 anos de imprensa regional: 1897 - 1997. Caxias do Sul, RS: Educs, 2004.

TESSARI, Anthony Beux. Imagens do labor: memória e esquecimento nas fotografias do trabalho da antiga metalúrgica Abramo Eberle (1896-1940). Porto Alegre, Dissertação de mestrado, PUCRS, 2013.

VALDUGA, Gustavo. Para além do coronelismo: italianos e descendentes na administração dos poderes executivos da região colonial italiana do Rio Grande do Sul (1924-1945). - Porto Alegre, Tese de doutorado. 2012.

VANNINI, I. A. História, sexualidade e crime: imigrantes e descendentes na Região Colonial Italiana do Rio Grande do Sul (1938/1958), Porto Alegre, PUCRS, 2008. 